\title{
Autoignition study of ULSD\#2 and FD9A diesel blends
}

\author{
Goutham Kukkadapu, Chih-Jen Sung \\ Department of Mechanical Engineering \\ University of Connecticut, Storrs, CT 06269
}

\begin{abstract}
Keywords: diesel, ULSD\#2 diesel, FD9A diesel, rapid compression machine, ignition delay time, low temperature combustion
\end{abstract}

Corresponding Author:

Goutham Kukkadapu

Department of Mechanical Engineering

University of Connecticut

191 Auditorium Road

Storrs, CT 06269-3139, USA

E-Mail: goutham.kukkadapu@uconn.edu

Phone: (860) 486-2492

Fax: (860) 486-5088

Submitted for publication in Combustion and Flame

Revised: December 22, 2015

Manuscript Reference Number: CNF-D-15-00746 


\author{
Autoignition study of ULSD\#2 and FD9A diesel blends \\ Goutham Kukkadapu, Chih-Jen Sung \\ Department of Mechanical Engineering, University of Connecticut, Storrs, CT 06269
}

\begin{abstract}
Autoignition study of two well-characterized reference diesel fuels with similar cetane ratings but different compositional characteristics has been conducted using a heated rapid compression machine (RCM). The two diesel blends used in the current study were a commercial grade ultralow-sulfur diesel (ULSD) \#2 reference fuel, ULSD\#2, and a Fuels for Advanced Combustion Engines (FACE) research diesel, FD9A. Ignition delay time measurements were conducted at compressed pressures of 10 bar, 15 bar, and 20 bar covering low-to-intermediate temperatures between $678 \mathrm{~K}$ and $938 \mathrm{~K}$. In addition, experiments were carried out with diesel $/ \mathrm{O}_{2} / \mathrm{N}_{2}$ mixtures at varying equivalence ratios of $\phi=0.5,0.69$, and 1.02 . Equivalence ratio was varied by changing the oxygen mole percentage while keeping the fuel mole percentage fixed at $0.514 \%$. Therefore, the present ignition delay time measurements illustrate the effect of oxygen concentration on diesel autoignition. The experimental results showed that diesel blends with similar cetane ratings and different compositional makeups exhibited varying ignition propensities in different temperature regimes, thereby demonstrating the effect of molecular composition on autoignition characteristics. In particular, the difference in ignition propensities was observed at temperatures at which the low temperature branching reactions are active. Furthermore, the ignition delay time measurements from the current RCM study were found to complement well with the existing shock tube data in the literature, and hence this investigation provides additional experimental database of diesel blends needed for development and validation of diesel surrogate models.
\end{abstract}




\section{Introduction}

Cetane ratings determined using the American Society for Testing and Materials (ASTM) standard test procedures, such as cetane number (CN) [1] and derived cetane number (DCN) [2], are widely used to quantify the ignition quality of a fuel. In the ASTM standard test procedures, liquid fuel is injected into hot oxidizer gases and the induction time for the mixture to ignite is measured. The induction time or the ignition delay time is then used to determine the cetane rating of a fuel. It is noted that this measured ignition delay time includes both physical and chemical induction times. The physical induction time is related to spray processes during which the liquid fuel breaks down into droplets, vaporizes, and mixes with hot oxidizer to form a combustible mixture. On the other hand, the chemical induction time relates to the time taken by the combustible mixture to ignite. The processes prevalent in the ASTM standard test procedures that are used to determine the cetane ratings are similar to those encountered in conventional compression ignition (CI) engines. Thus, the cetane rating of a fuel is a good metric to understand how a fuel would perform in a conventional CI engine. A recent computational study [3] has shown that for the induction times relevant to diesel fuels in the ASTM test vessels, the physical induction times are more dominating in controlling the ignition delays. Since the cetane rating is heavily influenced by physical processes, it may not be a good indicator of fuel ignition propensity in homogeneous ignition conditions.

Because of increasingly stringent engine emission standards, there is an urgent need to develop next-generation combustion technology with a focus on higher efficiency and reduced emissions. Advanced combustion technologies, such as low temperature combustion (LTC), are currently being pursued to develop such cutting-edge engines. The engines operating on LTC modes, such as partially premixed compression ignition (PPCI), are designed to operate at lower 
in-cylinder charge temperatures, greater degree of premixing, and higher dilution levels, which slow down the overall reactivity leading to ignition. Delaying the ignition timing results in increasing dominance of fuel chemistry and also leads to flame structure, heat release rate (HRR) profile, and temperature stratification that are different from those observed in conventional CI engines [4]. This increase in influence of ignition chemistry on the performance of LTC engines underscores the importance of understanding the autoignition characteristics of diesel fuels under LTC-relevant conditions, namely high pressures and low-to-intermediate temperatures.

Very few studies in the literature have focused on autoignition characteristics of diesel fuels. The literature studies that focused on ignition delay times of diesel fuels are listed in Table 1, including the facilities and the conditions of pressure, temperature, equivalence ratio, and dilution used in the experiments. Spadacinni and Tevelde [5] conducted ignition delay time measurements of diesel type fuels in a continuous flow reactor. The fuels studied in [5] included Jet-A, JP-4, n-cetane, No. 2 diesel, and a research grade diesel. The ignition delay time correlations deduced from their measurements showed that Jet-A was more reactive than No. 2 diesel [5]. Penyazkov et al. [6] measured ignition delay times of American commercial diesel (DF-2) using a pre-heated shock tube and compared the ignition delay times of DF-2 with those of Jet-A taken from Dean et al. [7]. The comparison of [6] showed that the ignition delay times of DF-2 were higher than those of Jet-A, with a factor of 2-6 difference depending on the conditions. Haylett et al. [8] conducted ignition delay time measurements of four different diesel blends, including a European grade diesel with $\mathrm{CN} \sim 55$ and three American grade diesels with DCN 42-46, in an aerosol shock tube to understand the effects of cetane rating and aromatic content percentage on ignition propensities. Haylett et al. [8] found that the differences in ignition delay times of the different diesel fuels tested to be small and that the ignition delay 
times generally decreased with increasing cetane rating. In addition, the measured ignition delay times of the American grade diesel fuel of $\mathrm{CN} \sim 43$ by Penyazkov et al. [6] and those by Haylett et al. [8] were seen to show a good agreement. Gowdagiri et al. [9] recently reported the ignition delay times of petroleum (F-76) and algae (HRJ-76) derived diesel blends. The two diesel blends used in [9] exhibited big differences in DCN values and compositions. Specifically, the DCN of F-76 was reported to be 48.8 , while that of HRJ-76 was reported to be 76 [9]. Despite the differences in DCN values and fuel compositions, Gowdagiri et al. [9] noticed that the ignition delay times of the two diesel blends were indistinguishable for temperatures greater than $1000 \mathrm{~K}$. Gowdagiri et al. [9] also observed that the petroleum derived diesel (F-76) and Jet-A exhibited identical ignition delay times across a wide range of temperatures they investigated.

Clearly, more ignition delay datasets of diesel reference fuels are needed in order to fully understand the effects of cetane rating and fuel composition on ignition propensities. Therefore, the objectives of the current study are two-fold. First, using a heated rapid compression machine, two fully-characterized diesel reference fuels with similar cetane rating but different compositional characteristics have been studied to explore the effect of fuel composition on ignition propensities by measuring and comparing their ignition delay times over a wide range of pressures and temperatures. The two diesel reference fuels used herein were a commercial grade ultra-low-sulfur diesel (ULSD) \#2 reference fuel, ULSD\#2, and a Fuels for Advanced Combustion Engines (FACE) research diesel, FD9A. These two diesel blends have been chosen as their cetane ratings are similar to those of the diesel fuels used in conventional diesel engines and they have received special attention from the engine community, especially the Coordinating Research Council (CRC). In addition, there are ongoing, concerted efforts in developing surrogates for these well-characterized diesel reference fuels and the associated chemical kinetic 
models. Hence, the second objective of this investigation is to provide benchmark ignition delay database of the two diesel fuels at varying pressures, oxygen concentrations, and temperatures needed for development and validation of surrogate models.

In the following, a detailed comparison of the properties and compositions of the two diesel blends used in the current study and those studied in the literature shall be first discussed. The experimental facility, its characterization, and the test matrix will be introduced and specified next, followed by the presentation and discussion of the present experimental results.

\section{Properties and compositions of diesel blends}

ULSD\#2 was obtained from Chevron Philips, while FD9A was acquired from the CRC. Table 2 shows and compares the properties and compositions of the two diesels used in the current study and F-76 used in [9]. It is noted that different types of analyses were conducted by the CRC to determine the compositions of the diesel blends, and the compositional characteristics of ULSD\#2 and FD9A from these different types of analyses documented in the CRC reports [1013] show noticeable differences in fuel composition for the given blend. Considering the differences in the reported compositions, the average values of the compositional characteristics from the latest report, determined using 2D GCMS [13], are listed in Table 2. The interested reader is referred to the original reports [10-13] for further details.

As seen from Table 2, while both ULSD\#2 and FD9A exhibit similar CN and DCN values, $\mathrm{H} / \mathrm{C}$ ratio, density, and heats of combustion, their compositions are different. In particular, FD9A contains higher amounts of aromatics accompanied by lower amounts of saturates when compared to ULSD\#2. However, in terms of weight percentage of paraffins ( $n$-alkanes $+i s o$ alkanes), both the blends constitute similar amounts $-34.82 \%$ in ULSD\#2 and 33.50\% in FD9A. 
Comparison of the weight percentages of the aromatic components shows that FD9A contains higher amounts of alkylbenzenes - more than double of that in ULSD\#2. In addition, 2D GCMS analysis of [13] showed that FD9A has high amounts of $\mathrm{C}_{8}-\mathrm{C}_{10}$ alkylbenzenes which constitute to about $75 \%$ of the total alkylbenzenes. It is also observed that ULSD\#2 consists of higher amounts of aromatics with more than two aromatic rings when compared to FD9A.

Further comparison of the properties and compositions of the diesel fuels used in the current study and in the literature studies has been conducted to understand their differences and similarities. When comparing the current experimental results with the literature data later on, this comparison can also provide insight into the effects of fuel composition on autoignition in different temperature regimes. Although Penzyazkov et al. [6] did not provide fuel property characterization for the commercial diesel No. 2 used in their study, their blend might be similar to the present ULSD\#2. In Haylett et al. [8], the DF-2 diesel blend used in their study was reported to be similar to the blend used by Penzyazkov et al. [6]. Since Gowdagiri et al. [9] reported the properties and compositions of the petroleum derived diesel F-76 used in their study, those values are shown and compared in Table 2. It is seen that while the H/C ratios of ULSD\#2, FD9A, and F-76 are similar, F-76 contains very high amounts of $n$-alkanes - a factor of 3.42-5.03 higher in terms of weight percentage. In regard to cetane rating comparison, only the DCN value of F-76 was reported in [9] and it is seen to be close to those of ULSD\#2 and FD9A, but with a higher value by about 5 units. 


\section{Experimental specifications}

\subsection{Rapid compression machine}

The present rapid compression machine (RCM) employs a creviced piston to compress a test mixture to elevated pressures and temperatures. This creviced piston is driven pneumatically and brought to rest by a hydraulic pin-groove mechanism towards the end of the compression stroke. While the typical compression times are around $3 \theta 45 \mathrm{~ms}$, the majority of pressure/temperature rise occurs in the last $6 \mathrm{~ms}$ of compression. A trigger from LabVIEW ${ }^{\circledR}$ initiates the compression event and starts data acquisition. Dynamic pressure in the reaction cylinder is measured using a thermal-shock resistant Kistler $6125 \mathrm{C}$ transducer in conjunction with a Kistler 5010B charge amplifier. Test gas mixture can be compressed to the desired test conditions at the end of compression, compressed pressure $\left(P_{C}\right)$ and compressed temperature $\left(T_{C}\right)$, by independently varying compression ratio, intake pressure $\left(P_{0}\right)$, and intake temperature $\left(T_{0}\right)$. Compression ratios varying between 4 and 17 can be attained by varying stroke length or/and clearance length.

The reaction cylinder is filled to the desired $P_{0}$ with a homogenous fuel/oxidizer mixture prepared in a separate stainless steel mixing chamber of $17.47 \mathrm{~L}$, which is equipped with heaters to preheat this test mixture to the desired $T_{0}$. When preparing a fuel/oxidizer mixture, the liquid diesel fuel is injected into the mixing chamber on a gravimetric measure using a syringe, while the gaseous oxidizer is prepared by filling the mixing chamber with constituent oxidizer gases to the corresponding partial pressures manometrically. The mass of liquid diesel fuel injected into the mixing chamber is determined based on the differential mass of the syringe before and after injection, measured using a mass balance with a least count of $0.01 \mathrm{gm}$. Ultra-high purity $(>99.99 \%) \mathrm{O}_{2}$ and $\mathrm{N}_{2}$ from Airgas are used to prepare homogenous diesel/oxidizer mixtures in this study. The mixing chamber, intake manifold, and reaction cylinder are heated to the desired 
preheat temperature for about 4 hours before starting the experiments. Additionally, the mixing chamber is equipped with a magnetic stirrer which aids in preparation of homogeneous mixtures. Further details about the current RCM design and test procedure can be found in Das et al. [14].

Figure 1 illustrates a representative experimental pressure trace exhibiting a two-stage ignition response and shows the definitions of the first-stage ignition delay $\left(\tau_{1}\right)$ and the total ignition delay $(\tau)$ used for reporting the present data. $\tau\left(\tau_{1}\right)$ is defined as the time difference between the end of compression (EOC) and the maxima of time derivative of the pressure after EOC corresponding to the hot ignition (the first-stage ignition). A minimum of four consecutive runs are conducted at each condition and the value close to the mean of the measured ignition delays is reported as the representative value. Figure 2 shows the comparison of the pressure trace records obtained using the ULSD\#2/air mixtures of equivalence ratio of $\phi=0.5$ prepared on three different days. The scatters in $\tau$ and $\tau_{1}$ are less than $15 \%$ of the representative values for all the cases investigated here.

\subsection{Estimation of compressed temperature $\left(T_{C}\right)$}

The compressed temperature $\left(T_{C}\right)$ was not measured directly and was deduced using the adiabatic core hypothesis:

$$
\int_{T_{0}}^{T_{c}} \frac{\gamma}{\gamma-1} \frac{d T}{T}=\ln \left(\frac{P_{c}}{P_{0}}\right)
$$

where $P_{C}, P_{0}$, and $T_{0}$ are measured values and $\gamma$ is the ratio of specific heats, which is temperature dependent. As such, estimation of compressed temperature requires prior knowledge of the thermodynamic properties of the test fuel. As the thermodynamic properties of transportation fuels are typically not available, the thermodynamic properties of their surrogates 
are often used for calculating reference temperatures in RCM and shock tube experiments. Gowdagiri et al. [9] used $n$-cetane as the thermodynamic surrogate for estimating the temperatures behind the reflected shock waves in their study. In the current study we used a three-component blend of 37\% n-cetane, 40\% iso-cetane, and 23\% 1-methyl naphthalene (by liquid volume) as the thermodynamic surrogate. This three-component blend was chosen as its $\mathrm{H} / \mathrm{C}$ ratio of 1.78 , molecular weight of $194.2 \mathrm{gm} / \mathrm{mol}$, and $\mathrm{DCN}$ (based on linear correlation by liquid volume) of 43 match closely with those of ULSD\#2 and FD9A (cf. Table 2). Gowdagiri et al. [9] pointed out in their study that the uncertainty in the estimated temperature due to the use of different thermodynamic properties of surrogates is very small $(\sim 1 \mathrm{~K})$. If $n$-cetane is used as the thermodynamic surrogate following [9], the typical difference in the estimated $T_{C}$ as compared to that using the three-component blend is $\sim 1 \mathrm{~K}$. Based on the error propagation analysis of [15], the total uncertainty in the estimated compressed temperature is about $\pm 5 \mathrm{~K}$, with the majority arising due to the uncertainty of $\pm 1.5 \mathrm{~K}$ in the initial temperature measurement.

\subsection{Test conditions}

Table 3 outlines the test conditions investigated in the current study. All the RCM experiments were conducted with mixtures of diesel $/ \mathrm{O}_{2} / \mathrm{N}_{2}$ at a fixed fuel mole percentage of $\mathrm{X}_{\text {diesel }}=0.514 \%$. The mole percentages of the fuel and $\mathrm{O}_{2}$ at a given equivalence ratio was calculated using the composition of diesel to be represented by $\mathrm{C}_{14} \mathrm{H}_{25.30}$, based on the molecular weight of $\sim 193.3$ $\mathrm{gm} / \mathrm{mol}$ calculated from the molecular composition of the constituents reported in [10] and the $\mathrm{H} / \mathrm{C}$ ratio of $\sim 1.80$. This estimated molecular weight of the diesel was found to match closely with that of the surrogate formulated by Mueller et al. [12]. For the current experiments, equivalence ratio was varied by varying the oxygen concentration while maintaining a fixed fuel 
loading. The oxygen concentrations investigated herein cover the range typical to engines operating with EGR [4]. The ignition delay time measurements conducted with varying concentrations of oxygen help in understanding the effect of dilution on autoignition. In addition, the compressed pressures and temperatures investigated were chosen to obtain ignition delay data complementary to the shock tube data in the literature, thereby facilitating comparison of ignition delay results over a wide range of conditions to understand the effect of fuel composition on ignition propensity.

\subsection{Vaporization checks}

When constructing the present test conditions, theoretical and experimental exercises were conducted to ensure that the diesel fuel injected to the mixing chamber vaporized completely. Our earlier studies have experimentally shown the present mixture preparation method to be adequate without fuel condensation [14,16,17]. In a theoretical effort to examine the potential condensation issue when handling a diesel fuel, the partial pressures of the constituents of the diesel blend were calculated and compared to the corresponding saturated vapor pressures at a given preheat temperature. These partial pressure calculations used the ideal gas law and the mole percentages of the constituents deduced from the weight percentage information available in [10]. In addition, the saturated vapor pressure of each constituent considered was obtained from [18]. Calculations showed that for the molar composition of the diesel fuel tested, the preheat temperature of $420 \mathrm{~K}$ is sufficiently high to ensure complete vaporization of all the components for the diesel fuel injected into the mixing chamber when the total pressure of the fuel is less than 14 Torr. 
With a chamber preheat temperature of $420 \mathrm{~K}$, Fig. 3 shows the time variation of chamber pressure measured using a pressure transducer after a known mass of diesel fuel was injected into the heated mixing chamber. The pressure computed from the ideal gas law assuming that the diesel fuel injected into the heated mixing chamber has completely vaporized, which is about 13 Torr, is also indicated in Fig. 3 as a reference. Moreover, the error bars shown in Fig. 3 correspond to the uncertainty in pressure measurements which is about $0.05 \%$ of the full scale reading of the transducer ( $0-5200$ Torr), namely \pm 2.6 Torr. It is seen from Fig. 3 that the majority of the diesel fuel, more than $85 \%$, vaporizes instantly in the mixing chamber and subsequently the pressure in the mixing chamber rises gradually to more than $95 \%$ of the expected value in an hour. Similar trend was also observed when increasing the preheat temperature to $430 \mathrm{~K}$.

There could be several possible reasons causing the gradual increase in chamber pressure after fuel injection. Regarding the likelihood of fuel decomposition, the rate of fuel decomposition/pyrolysis at the current preheat temperature was estimated to be in the order of $10^{-18}-10^{-11} \mathrm{~s}^{-1}$, based on the rates from the recent experimental study of [19]. Such a low rate of fuel decomposition, along with low chamber pressure, would imply a negligible change in fuel composition. Even with the present of oxidizer, the pre-oxidation of the fuel in the heated mixing chamber is not expected to be of major concern. Thus, we can safely assume that the fuel is unchanged over the period of mixture preparation. Although we cannot completely rule out the possibility that some of the fuel components can be adsorbed onto the walls of the mixing chamber, thereby leading to fuel loss and accounting for the discrepancy in the expected and measured chamber pressures, it is argued that the gradual increase in chamber pressure could be primarily caused by preferential/slow vaporization of the heavier components. From the 
monitoring of the mixing chamber pressure, it is clear that more than $95 \%$ of the injected fuel has vaporized, indicating that the uncertainty in the nominal equivalence ratio is about $5 \%$ for the current experiments, which has been shown to be a typical uncertainty in equivalence ratio for preparation of homogenous liquid fuel/oxidizer mixtures in our previous study [16]. Ultimately, a detailed composition analysis, using GC, MS, FID, etc., should be conducted to confirm the assumptions of minimal/negligible fuel loss, mixture homogeneity, and non-decomposition of fuel in the heated mixture chamber, as demonstrated in our previous RCM study on $n$-decane [16]. However, for fully-blended transportation fuels in general and diesel fuels in particular, developing the required protocol/procedure to avoid fuel condensation/loss during sampling and reduce the associated accuracy/uncertainty is challenging, and hence merits further studies.

Further experimental checks were conducted to ensure that the diesel fuel did not condense in the heated RCM. In this series of experimental checks, RCM experiments were conducted using diesel/air and gasoline/air mixtures with similar operating parameters, $P_{C}$, and $T_{C}$. It is noted that the fuel/air mixtures were prepared and heated to the desired preheat temperatures in the mixing chamber for about 4 hours before the subsequent RCM experiments. FD9A diesel and FACE A gasoline were used, and their measured pressure traces in RCM reactive experiments were compared. Since both FD9A and FACE A exhibit similar heat of combustion values and stoichiometric fuel/air mass ratios, it is expected that when diesel/air and gasoline/air mixtures with an identical equivalence ratio are ignited in the RCM, their post hot-ignition pressures should be comparable if each fuel has vaporized completely. Comparison of pressure traces of FD9A/air and FACE A/air mixtures at $\phi=0.5$ and FACE A/air mixture at $\phi=0.4$ is shown in Fig. 4, at almost identical compressed pressure and compressed temperature. It can be seen from Fig. 4 that at $\phi=0.5$ in air the post-hot ignition peak pressures of FD9A diesel and more volatile 
FACE A gasoline are nearly identical. In addition, the post-hot ignition peak pressure of $\phi=0.4$ FACE A/air mixture is significantly lower than those of $\phi=0.5$ mixtures, thereby indicating that the equivalence ratio of the FD9A/air mixture is much closer to $\phi=0.5$ than $\phi=0.4$. Based on these theoretical and experimental exercises, we are confident that the condensation of diesel fuel is not an issue in the current experimental facility.

\section{Experimental results and discussion}

\subsection{Ignition characteristics of ULSD\#2 and FD9A}

Figures 5(a) and 5(b) show the raw pressure records of ULSD\#2 and FD9A, respectively, at $\phi=0.5$ in air, $P_{C}=10$ bar, and various compressed temperatures. Both diesel fuels are seen to exhibit two-stage ignition characteristics in the temperature range investigated. Moreover, the ignition delays of both diesel blends appear to decrease monotonically with increasing temperature for $T_{C}<720 \mathrm{~K}$ - this temperature window is therefore referred as the low temperature regime (LTR). A negative temperature coefficient (NTC) behavior is observed for $T_{C}$ in the range of $720-833 \mathrm{~K}$, as in this temperature range the ignition delay increases with increasing temperature. For $T_{C}>833 \mathrm{~K}$, the ignition delay starts to decrease monotonically with increasing temperature, and hence this temperature window is referred as the intermediate temperature regime (ITR). The RCM pressure traces with $\phi=0.5$ diesel/air mixtures at $P_{C}=20$ bar are shown in Figs. 5(c) and 5(d), while the experimental results are limited to $T_{C}<707 \mathrm{~K}$ as further increase in compressed temperature led to the initiation of ignition during the compression stroke. At this higher compressed pressure, two-stage ignition characteristics are also observed in the LTR for both ULSD\#2 and FD9A. It is noted that the ignition delays and pressure records for the 
compressed conditions at which ignition events were initiated during the compression stroke have been discarded and not reported in the current study.

Figure 6 shows the ignition delays of $\phi=0.5$ diesel/air mixtures of both ULSD\#2 and FD9A at varying compressed pressures and compressed temperatures. Again, the ignition delays shown in Fig. 6 were deduced from the measured pressure traces according to the definitions demonstrated in Fig. 1. The error bars displayed in Fig. 6 represent the uncertainty of $\pm 15 \%$ in the deduced ignition delays, as discussed earlier. The ignition delays, both first-stage and total ignition delays, were observed to decrease with increasing pressure. Additionally, the first-stage ignition delays were seen to decrease monotonically with increasing temperature, while the total ignition delays exhibited an NTC response for compressed temperatures in the range of $T_{C}=720$ $833 \mathrm{~K}$ at $P_{C}=10$ bar.

Figure 7 shows the effect of oxygen concentration on the reactivity of ULSD\#2 and FD9A at different test conditions by keeping the fuel loading constant. It is seen from Fig. 7 that the total and first-stage ignition delays increase with an increase (a decrease) in equivalence ratio (oxygen concentration). Comparison of the ignition delays at the conditions shown in Fig. 7 illustrates that the total ignition delays are more sensitive to the change in oxygen concentration for compressed temperatures in the LTR and within the NTC regime. It is well known that for compressed temperatures in the NTC regime and LTR, reactivity is controlled by the addition of oxygen molecules $\left(\mathrm{O}_{2}\right)$ to fuel radicals $(\mathrm{R})$ which leads to the formation of peroxy adducts $\left(\mathrm{RO}_{2}\right)$. A decrease in oxygen concentration is expected to reduce the effectiveness of these reactions, thus reducing the fuel reactivity. Such an effect of oxygen concentration on autoignition is clearly understood by the comparison of pressure traces shown in Fig. 8 for both diesel blends at $P_{C}=20$ bar and $T_{C}=678 \mathrm{~K}$. It can be observed that for this LTR compressed temperature, the 
decrease (increase) in oxygen concentration (equivalence ratio) results in an increase in $\tau_{1}$ and a reduction in the pressure rise due to the first-stage ignition. A higher first-stage pressure rise would imply a higher resulting temperature due to the first-stage ignition and a larger radical pool, both of which are known to accelerate the second-stage ignition (or hot ignition).

For compressed temperatures in the ITR, the $\beta$-decomposition reactions of fuel radicals start to compete with the reactions leading to the formation of peroxy adducts, resulting in a reduction of the sensitivity of the total ignition delay to the change in concentration of oxygen, as shown in Fig. 7. The dependence of total ignition delays of diesel fuels on oxygen concentration observed in the current study are consistent with those observed in gasoline fuels [20-23] and jet fuels [24,25]. The summary of the ignition delay measurements of ULSD\#2 and FD9A conducted in this study at varying pressures, temperatures, and equivalence ratios is provided as supplementary material.

\subsection{Comparison of ignition delays of ULSD\#2 and FD9A}

Figure 9 compares the ignition delays of the two research grade diesel fuels used in the current study. The first-stage ignition delays of the two blends were observed to be very similar at conditions tested. However, the total ignition delay comparison shows an interesting trend that is dependent on the temperature range of interest. In particular, the total ignition delays of FD9A were found to be higher than those of ULSD\#2 for temperatures in the LTR, with the differences being less than $25 \%$. The higher total ignition delays of FD9A and its relatively lower reactivity at low temperatures could be because it contains large amounts of aromatics, particularly the higher amounts of $\mathrm{C}_{8}-\mathrm{C}_{10}$ alkyl benzenes (about $17 \%$ by weight). The differences in the total ignition delays of ULSD\#2 and FD9A appear to reduce with increasing temperature, and the 
total ignition delays of the two blends become indistinguishable for temperatures in the ITR. It is also of interest to note that at temperatures around $820 \mathrm{~K}$, the temperature range at which the ASTM standard test procedure [2] is conducted to determine the DCN rating, the total ignition delays of the two blends are very similar. This ignition delay similarity in turn indicates that DCN ratings are good metrics of fuel reactivity at temperatures other than in the LTR.

The current experimental results show that the effect of fuel composition on ignition propensity is more pronounced at low temperatures than at intermediate-to-high temperatures. The observed trends can be attributed to the fact that the chain branching reactions which control ignition at low temperatures are more sensitive to the compositional characteristics. Won et al. [26] have recently shown that the binary blends of $n$-cetane/iso-cetane and $n$-dodecane/isooctane with similar DCN ratings exhibited differences in total ignition delays in the LTR and NTC while their total ignition delays were identical for temperatures in the ITR. Their observed trends in reactivity were attributed to the fuel structure effects [26]. At high temperatures, ignition is controlled by the smaller radical species formed from the breaking down of the fuel molecules, and hence the dependence of ignition propensity on the parent fuel structure is weakened, as noted by Dooley et al. [27].

\subsection{Comparison of current total ignition delay data and literature results}

Figure 10 shows the comparison of the total ignition delay measurements from the current study and those reported in the literature. In Fig. 10(a), the current RCM data are compared with the shock tube results of Haylett et al. [8]. Haylett et al. [8] conducted experiments at a nominal pressure of 6 atm, while the current set of experiments were conducted at a compressed pressure of $P_{C}=10$ bar. For the purpose of comparison, the shock tube ignition delays were scaled to 10 
bar using the scaling factor suggested by Haylett et al. [8]. It can be observed from Fig. 10(a) that the current RCM measurements of the two blends at lower temperatures complement well with the shock tube measurements from Haylett et al. [8] at higher temperatures. In addition, since Haylett et al. [8] conducted their experiments at conditions in the ITR and higher temperatures, the ignition delay measurements of diesel blends with similar cetane ratings should be similar. This explains the complementary nature of ignition delays from the current study and those from Haylett et al. [8], as the diesel fuels compared have similar cetane ratings despite different compositional characteristics.

Figure 10(b) compares the total ignition delays of ULSD\#2, FD9A, and F-76. At compressed temperature of $T_{\mathcal{C}} \sim 707 \mathrm{~K}$, the total ignition delay of F-76 measured by Gowdagiri et al. [9] appears to be about a factor of 2 lower than the current results of ULSD\#2 and FD9A. This total ignition delay discrepancy could be primarily due to the differences in fuel composition. As discussed earlier and shown in Table 2, F-76 has about 56\% (by weight) of $n$ alkanes, while ULSD\#2 and FD9A contain less than 17\% (by weight). The high amounts of $n$ alkanes in F-76 are expected to promote chain-branching, low-temperature reactivity [9], thereby resulting in shorter ignition delays.

\section{Conclusions}

Using a heated RCM, autoignition experiments with two research grade diesel fuels, namely ULSD\#2 and FD9A, have been conducted in the current study to investigate the effect of fuel composition on ignition propensity. The experimental results show that the differences in fuel composition could affect ignition propensities at temperatures where low temperature reactions are dominant. The current experiments also help in understanding the autoignition characteristics 
of diesel fuels, as well as proving validation database covering low-to-intermediate temperatures and elevated pressures for the formulation of diesel surrogates and the development of surrogate kinetic models. Experiments with changes in oxygen concentration, while keeping the fuel loading constant, show that both the first-stage and total ignition delays increase with decreasing oxygen concentration, with the total ignition delays being more sensitive to oxygen concentration variation than the first-stage ignition delays. To our knowledge, this work is the first time that the first-stage ignition delays of diesel fuels have been reported. Furthermore, the ignition delay measurements from the current RCM study are shown to complement well with the existing shock tube data in the literature.

\section{Acknowledgements}

This work was supported by the National Science Foundation under Grant No. CBET-1402231. We would like to thank Drs. Marco Mehl and William J. Pitz at Lawrence Livermore National Laboratory for helpful discussions, as well as Mr. Jonathan VanScoyoc at Chevron Phillips and Dr. William J. Cannella at Chevron for providing us the samples of ULSD\#2 and FD9A, respectively. 


\section{References}

1. ASTM D613-15, Standard Test Method for Cetane Number of Diesel Fuel Oil, ASTM International, West Conshohocken, PA, 2015.

2. ASTM D6890-15, Standard Test Method for Determination of Ignition Delay and Derived Cetane Number (DCN) of Diesel Fuel Oils by Combustion in a Constant Volume Chamber, ASTM International, West Conshohocken, PA, 2015.

3. G. E. Bogin Jr., E. Osecky, M. A. Ratcliff, J. Luecke, X. He, B. T. Zigler, A. M. Dean, Ignition quality tester (IQT) investigation of the negative temperature coefficient region of alkane autoignition, Energy and Fuels 27 (2013) 1632-1642.

4. M. P. B. Musculus, P. C. Miles, L. M. Pickett, Conceptual models for partially premixed low - temperature diesel combustion, Progress in Energy and Combustion Science 39 (2013) 246-283.

5. L. J. Spadaccini, J. A. Tevelde, Autoignition characteristics of aircraft-type fuels, Combustion and Flame 46 (1982) 283-300.

6. O. G. Penyazkov, K. L. Sevruk, V. Tangirala, N. Joshi, Autoignitions of diesel fuel/air mixtures behind reflected shock waves, Proceedings of the 4th European combustion meeting, Vienna, Austria; 2009.

7. A. J. Dean, O. G. Penyazkov, K. L. Sevruk, B. Varatharajan, Autoginition of surrogate fuels at elevated temperatures and pressures, Proceedings of the Combustion Institute, 31 (2007) 2481-2488.

8. D. R. Haylett, D. F. Davidson, R. K. Hanson, Ignition delay times of low-vapor pressure fuels measured using an aerosol shock tube, Combustion and Flame 159 (2012) 552-61. 
9. S. Gowdagiri, W. Wang, M. A. Oehlschlaeger, A shock tube ignition delays study of conventional diesel fuel and hydroprocessed renewable diesel fuel from algal oil, Fuel 128 (2014) 21-29.

10. M. Alnajjar, W. Cannella, H. Dettman, C. Fairbridge, J. Franz, T. Gallant, R. Gieleciak, D. Hager, C. Lay, S. Lewis, M. Ratcliff, S. Sluder, J. Storey, H. Yin, B. Zigler, Chemical and Physical Properties of the Fuels for Advanced Combustion Engines (FACE) Research Diesel Fuels, FACE-1; Coordinating Research Council: Alpharetta, GA, 2010.

11. W. Cannella, C. Fairbridge, R. Gieleciak, P. Arboleda, T. Bays, H. Dettman, M. Foster, G. Gunter, D. Hager, D. King, C. Lay, S. Lewis, J. Luecke, S. Sluder, B. Zigler, B. Natarajan, Advanced Alternative and Renewable Diesel Fuels: Detailed Characterization of Physical and Chemical Properties, Coordinating Research Council: Alpharetta, GA, 2013.

12. C. J. Mueller, W. J. Cannella, T. J. Bruno, B. Bunting, H. D. Dettman, J. A. Franz, M. L. Huber, M. Natarajan, W. J. Pitz, M. A. Ratcliff, K. Wright, Methodology for formulating diesel surrogate fuels with accurate compositional, ignition quality and volatility characteristics, Energy \& Fuels 26 (2012) 3284-3303.

13. R. Gielciak, C. Fairbridge, Detailed hydrocarbon analysis of FACE diesels using comprehensive two-dimensional gas chromatography. http://www.crcao.com/publications/advancedVehiclesFuelsLubricants/FACE/index.html.

14. A. K. Das, C. J. Sung, Y. Zhang, G. Mittal, Ignition delay study of moist hydrogen/oxidizer mixtures using a rapid compression machine, International Journal of Hydrogen Energy, 37 (2012) 6901-6911.

15. B. W. Weber, C. J. Sung, M. W. Renfro, On the uncertainty of temperature estimation in a rapid compression machine, Combustion and Flame 162 (2015) 2518-2528. 
16. K. Kumar, G. Mittal, C. J. Sung, Autoignition of $n$-decane under elevated pressure and lowto-intermediate temperature conditions, Combustion and Flame 156 (2009) 1278-1288.

17. B. W. Weber, K. Kumar, Y. Zhang, C. J. Sung, Autoignition of $n$-butanol at elevated pressure and low to intermediate temperature, Combustion and Flame 158 (2011) 809-819.

18. C. L. Yaws, Yaw's Handbook of Thermodynamic and Physical Properties of Chemical Compounds, 2003, Knovel.

19. M. E. MacDonald, W. Ren, Y. Zhu, D. F. Davidson, R. K. Hanson, Fuel and ethylene measurements during $n$-dodecane, methylcyclohexane, and iso-cetane pyrolysis in shock tubes, Fuel 103 (2013), 1060-1068.

20. G. Kukkadapu, K. Kumar, C. J. Sung, M. Mehl, W. J. Pitz, Experimental and surrogate modeling study of gasoline ignition in a rapid compression machine, Combustion and Flame 159 (2012) 3066-3078.

21. G. Kukkadapu, K. Kumar, C. J. Sung, M. Mehl, W. J. Pitz, Autoignition of gasoline and its surrogates in a rapid compression machine, Proceedings of Combustion Institute 34 (2013) 345-352.

22. S. M. Sarathy, G. Kukkadapu, M. Mehl, W. Wang, T. Javed, S. Park, M. A. Oehlschlaeger, A. Farooq, W. J. Pitz, C. J. Sung, Ignition of alkane-rich FACE gasoline fuels and their surrogate mixtures, Proceedings of the Combustion Institute 34 (2015) 249-257.

23. G. Kukkadapu, K. Kumar, C. J. Sung, M. Mehl, W. J. Pitz, Autoignition of gasoline surrogates at low temperature combustion conditions, Combustion and Flame 162 (2015) $2272-2285$. 
24. K. Kumar, C. J Sung, An experimental study of the autoignition characteristics of conventional jet fuel/oxidizer mixtures: Jet-A and JP-8. Combustion and Flame 157 (2010) $676-85$.

25. K. Kumar, C. J. Sung, A comparative experimental study of the autoignition characteristics of alternative and conventional jet fuel/oxidizer mixtures, Fuel 89 (2010) 2853-2863.

26. S. H. Won, S. Dooley, P. S. Veloo, H. Wang, M. A. Oehlschlaeger, F. L. Dryer, Y. Ju, The combustion properties of 2,6,10 trimethyl dodecane and a chemical functional group analysis, Combustion and Flame 161 (2014) 826-864.

27. S. Dooley, S. H. Won, J. Heyne, T. I. Farouk, Y. Ju, F. L. Dryer, K. Kumar, X. Hui, C. J. Sung, H. Wang, M. A. Oehlschlaeger, V. Iyer, S. Iyer, T. A. Litzinger, R. J. Santoro, T. Malewicki, K. Brezinsky, The experimental evaluation of a methodology for surrogate fuel formulation to emulate gas phase combustion kinetic phenomena, Combustion and Flame 159 (2012) 1444-1466. 


\section{List of Figures}

Figure 1: Plot showing the definitions of first-stage ignition delay $\left(\tau_{1}\right)$ and total ignition delay $(\tau)$ used in the current study. Conditions: ULSD\#2/air, $\phi=0.5, P_{C}=20$ bar, and $T_{C}=678 \mathrm{~K}$.

Figure 2: Plot demonstrating the repeatability of the current ignition delay measurements. Conditions: ULSD\#2/air, $\phi=0.5, P_{C}=20$ bar, and $T_{C}=678 \mathrm{~K}$.

Figure 3: Plot showing the measured pressures in the mixing chamber after liquid fuel injection. The pressure expected from complete fuel vaporization calculated using the ideal gas law is also shown as a reference.

Figure 4: Comparison of measured pressure traces of ignition of FACE A gasoline and FD9A diesel at similar compressed conditions of $P_{C}=20$ bar and $T_{C} \sim 700 \mathrm{~K}$.

Figure 5: Plots showing the pressures traces of ULSD\#2 and FD9A for $\phi=0.5$ in air at varying compressed temperatures and pressures.

Figure 6: Arrhenius plots of ignition delays $\left(\tau_{1}\right.$ and $\tau$ ) of $\phi=0.5$ diesel/air mixtures at $P_{C}=10$ and 20 bar - (a) ULSD\#2 and (b) FD9A.

Figure 7: Arrhenius plots of ignition delays $\left(\tau_{1}\right.$ and $\left.\tau\right)$ of ULSD\#2 and FD9A at varying compressed pressures and equivalence ratios (i.e. oxygen mole percentages). The fuel mole percentage is kept constant at $0.514 \%$.

Figure 8: Compression of pressure traces at $P_{C}=20$ bar and $T_{C}=678 \mathrm{~K}$ with $\phi=0.5$ and 1.02 by varying oxygen mole percentage - (a) ULSD\#2 and (b) FD9A. The fuel mole percentage is kept constant at $0.514 \%$.

Figure 9: Comparison of ignition delays ( $\tau_{1}$ and $\tau$ ) of ULSD\#2 and FD9A at varying compressed pressures and equivalence ratios (i.e., oxygen mole percentages). The fuel mole percentage is kept constant at $0.514 \%$.

Figure 10: Comparison of total ignition delays of ULSD\#2, FD9A, and literature diesel blends at (a) $P_{C}=10$ bar and $\phi=0.5$ and (b) $P_{C}=20$ bar and $\phi=0.5$. 


\section{List of Tables}

Table 1: List of literature studies on autoignition of diesel blends.

Table 2: Comparison of properties and compositions of the diesel blends used in the current study and in Gowdagiri et al. [9].

Table 3: Test conditions investigated in the current study. 


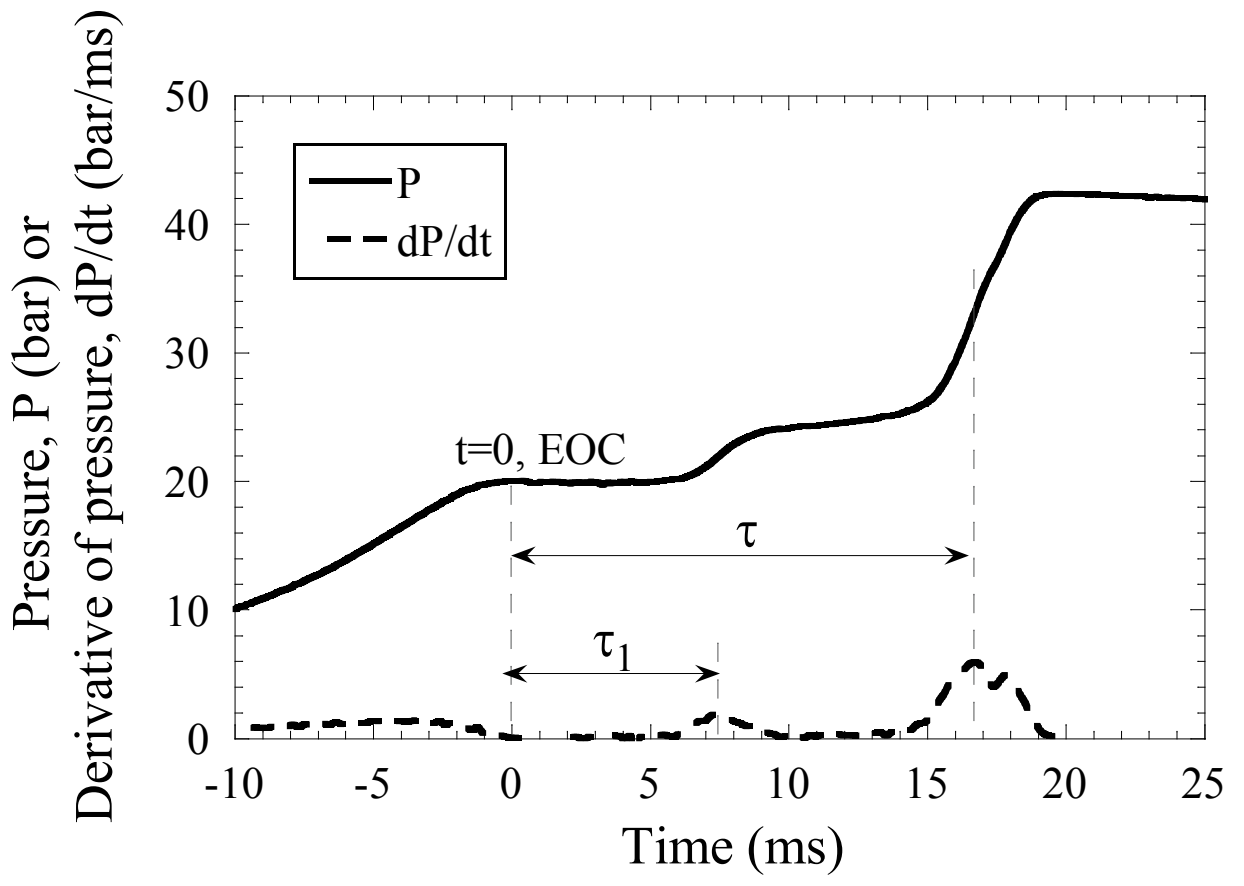

Figure 1 


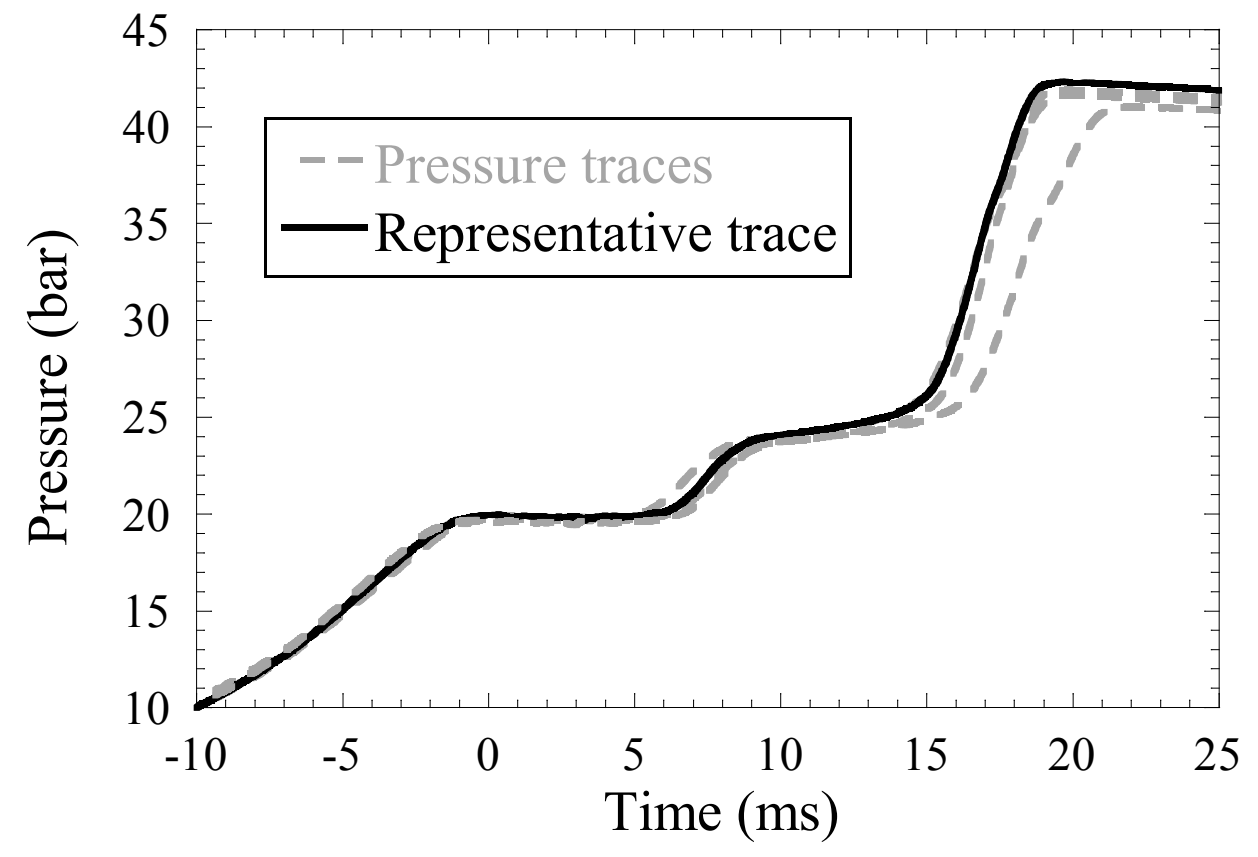

Figure 2 


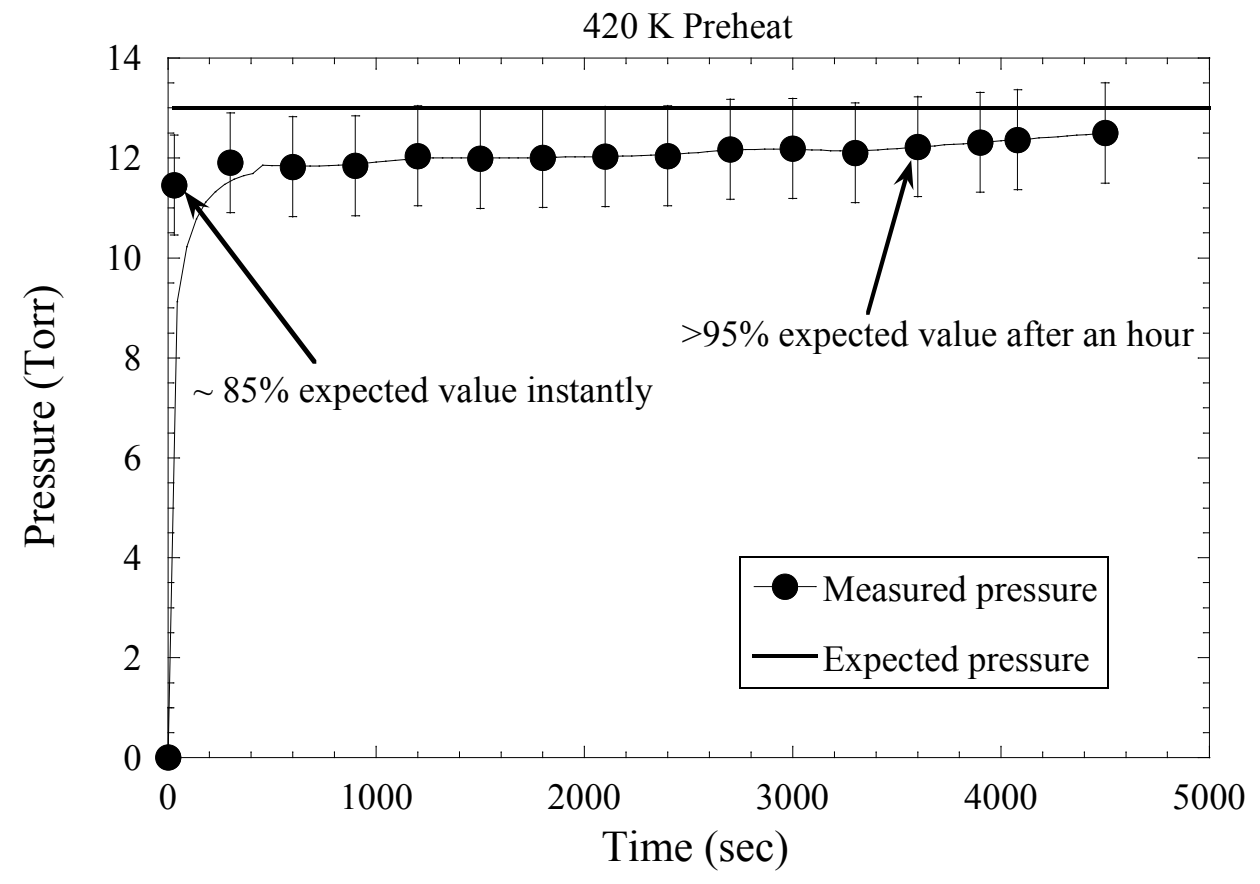

Figure 3 


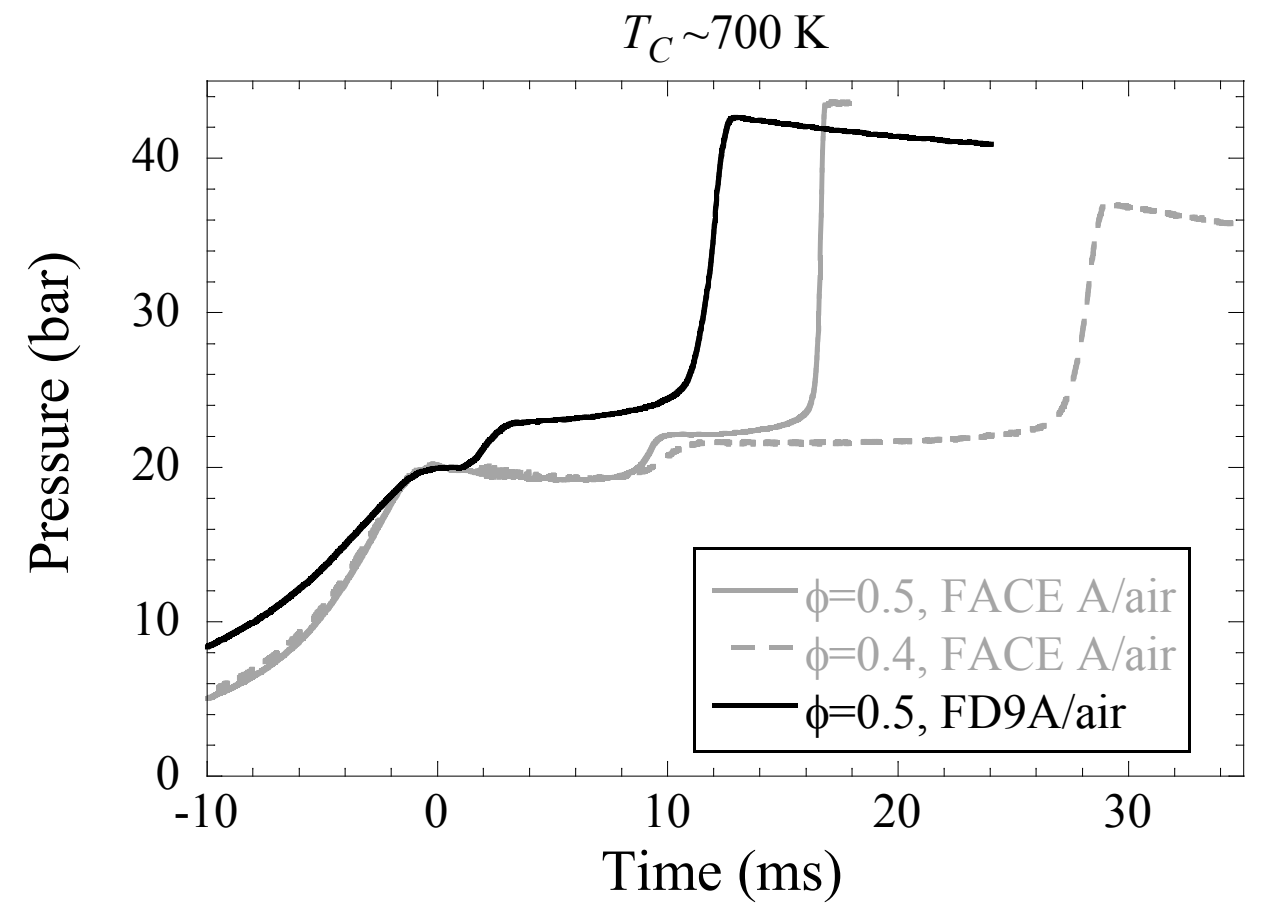

Figure 4 


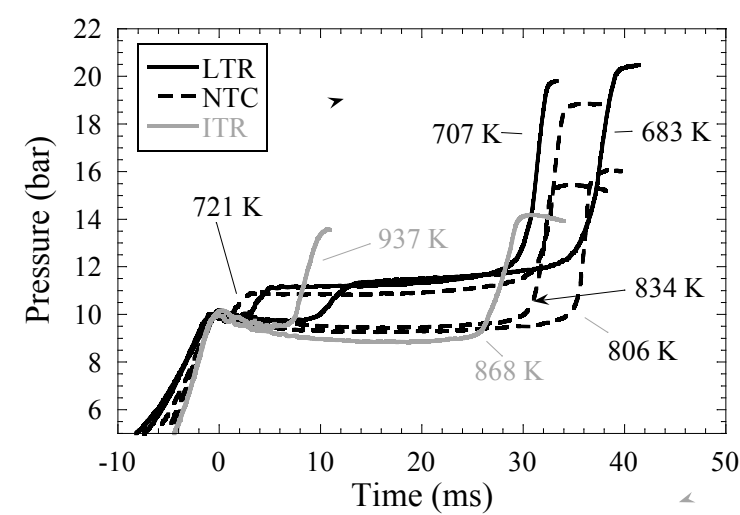

(a) $\phi=0.5, P_{C}=10$ bar, ULSD\#2/air mixtures

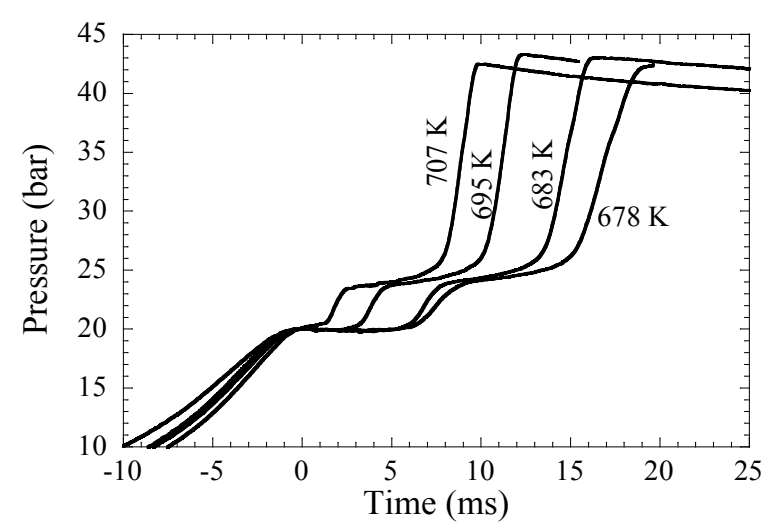

(c) $\phi=0.5, P_{C}=20$ bar, ULSD\#2/air mixtures

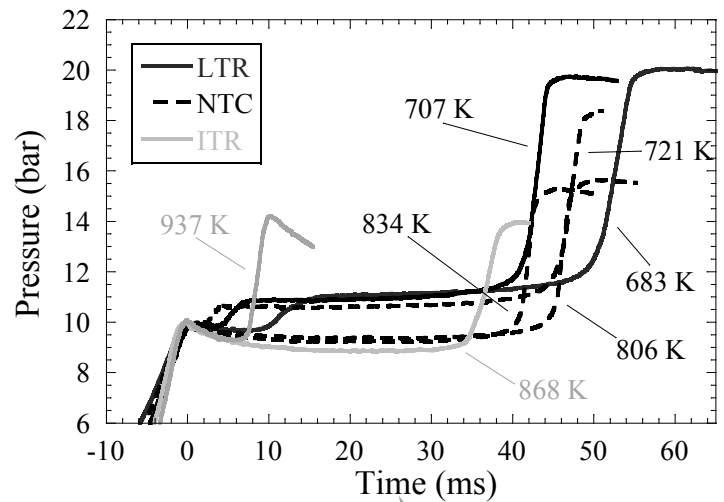

(b) $\phi=0.5, P_{C}=10$ bar, FD9A/air mixtures

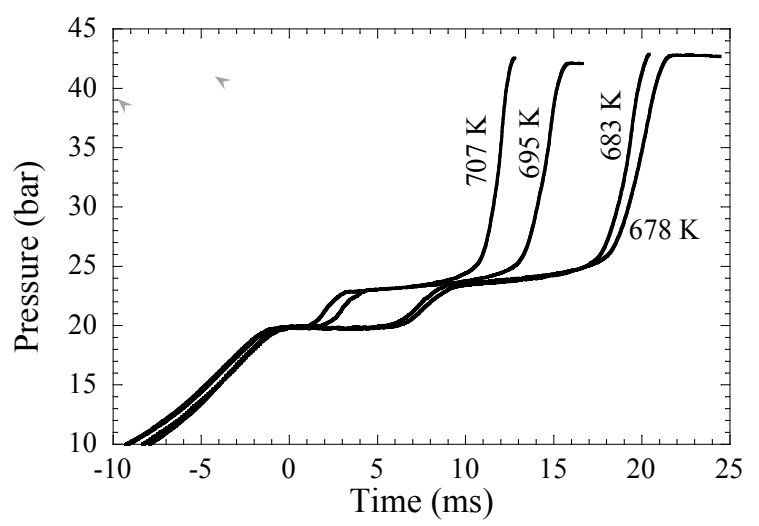

(d) $\phi=0.5, P_{\mathrm{C}}=20$ bar, FD9A/air mixtures

Figure 5 


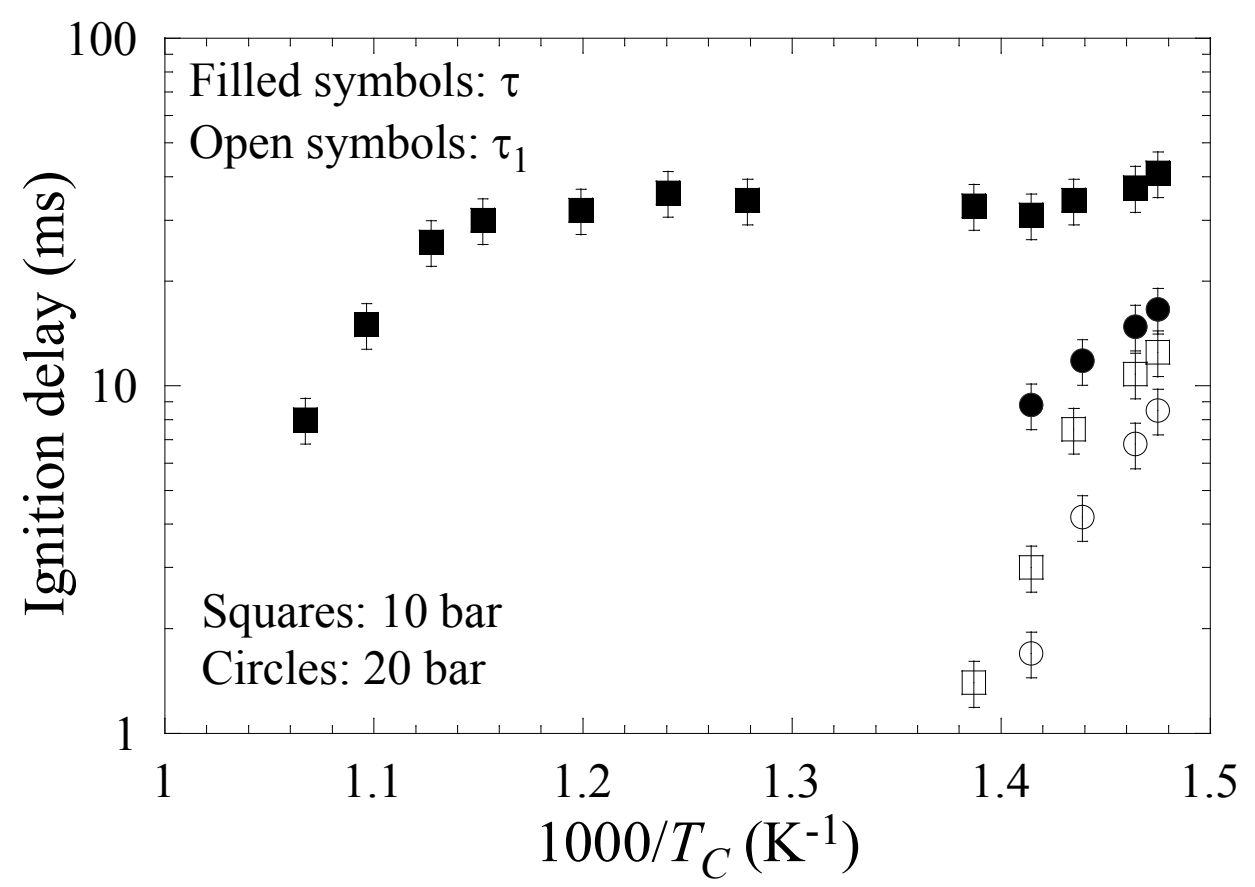

(a) $\phi=0.5$, ULSD \#2

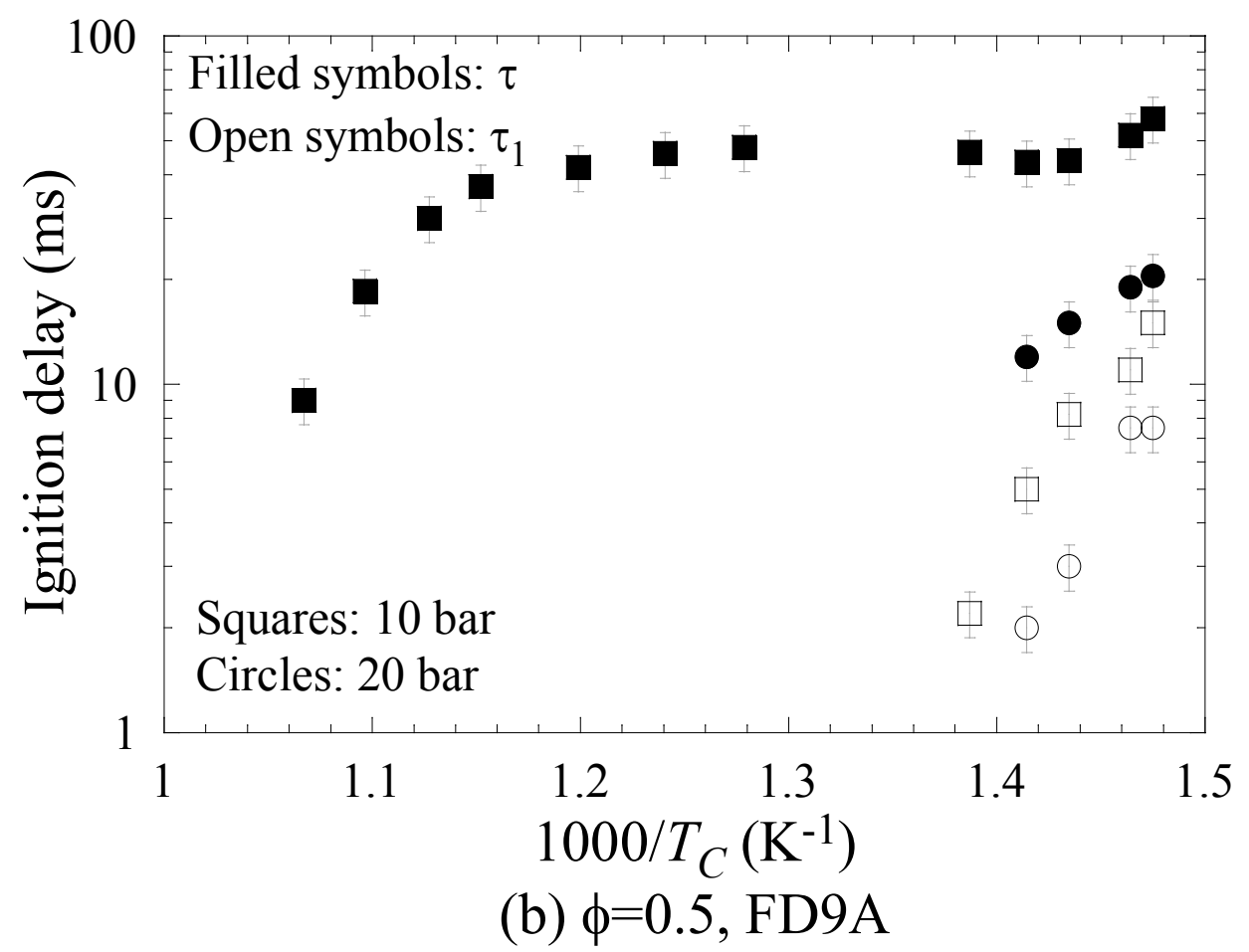

Figure 6 


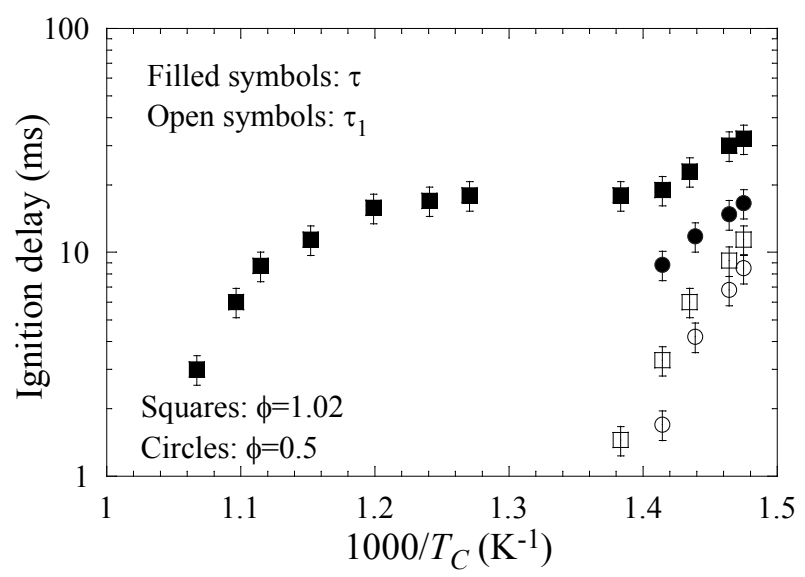

(a) $P_{C}=20$ bar, ULSD\#2

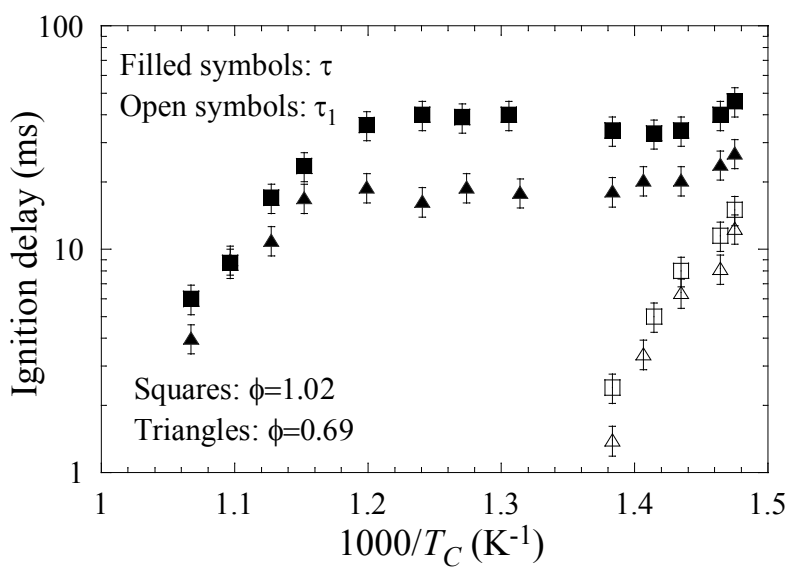

(c) $P_{C}=15$ bar, ULSD\#2

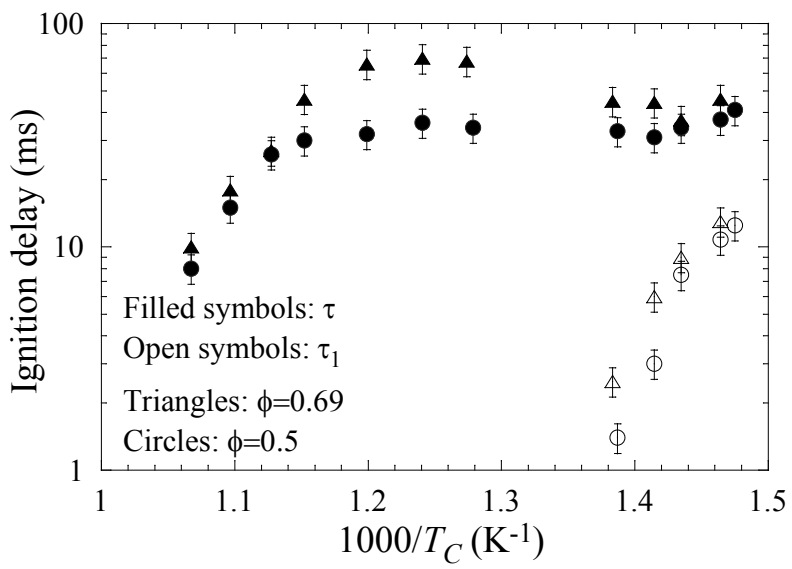

(e) $P_{C}=10$ bar, ULSD\#2

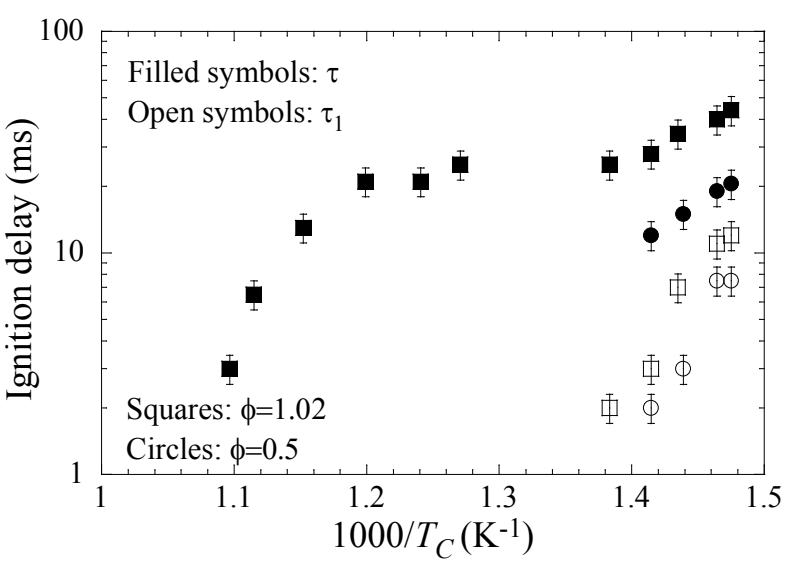

(b) $P_{C}=20$ bar, FD9A

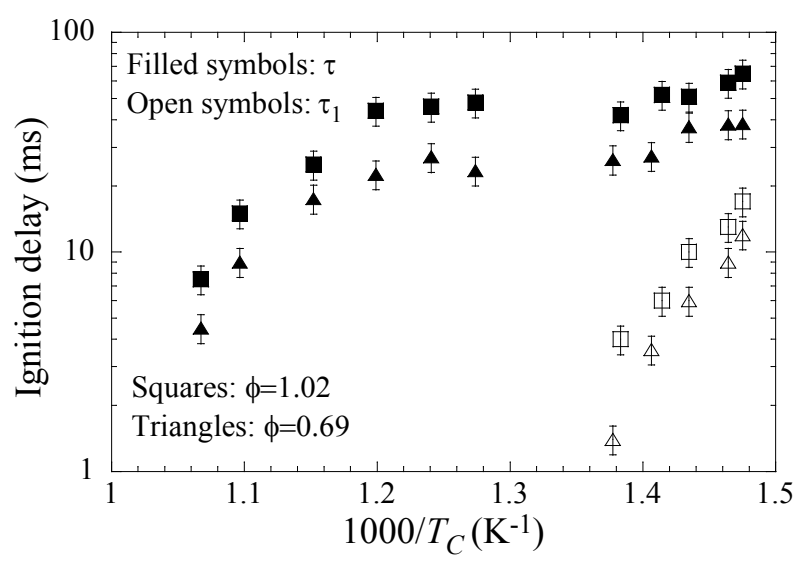

(d) $P_{C}=15$ bar, FD9A

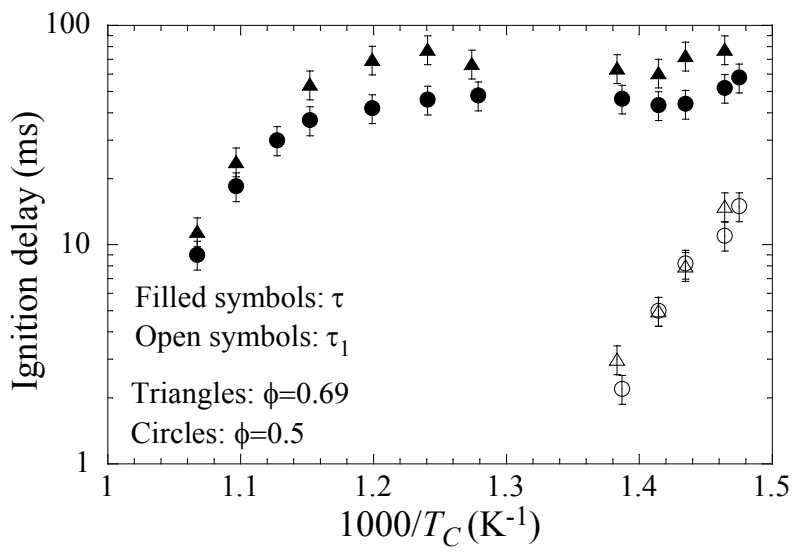

(f) $P_{C}=10$ bar, FD9A

Figure 7 


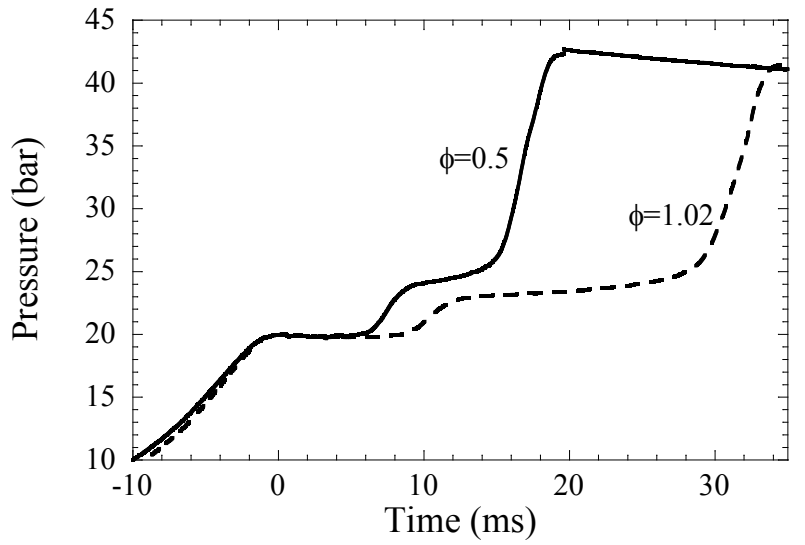

(a) $T_{C}=678 \mathrm{~K}$, ULSD $\# 2 / \mathrm{O}_{2} / \mathrm{N}_{2}$ mixtures

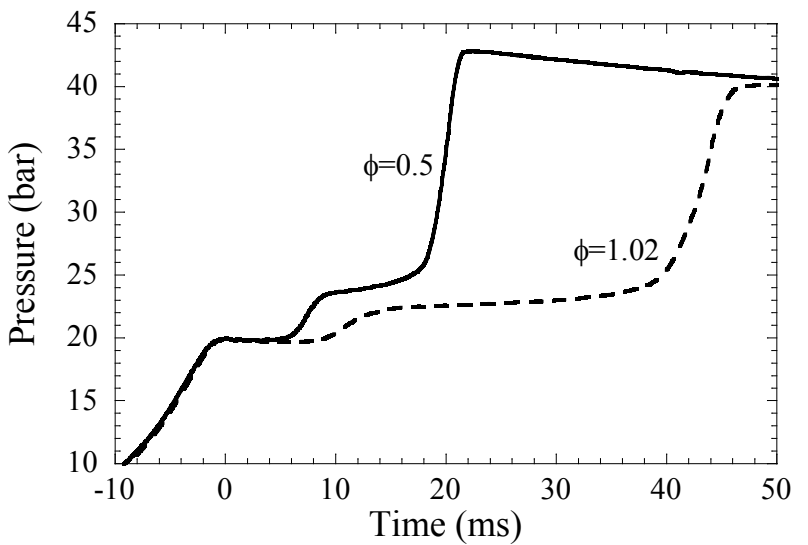

(b) $T_{C}=678 \mathrm{~K}, \mathrm{FD} 9 \mathrm{~A} / \mathrm{O}_{2} / \mathrm{N}_{2}$ mixtures

Figure 8 


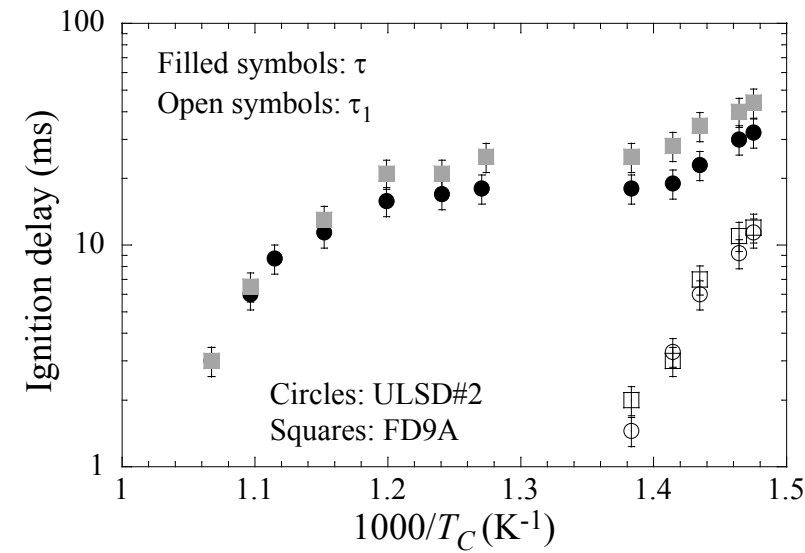

(a) $\phi=1.02, P_{C}=20$ bar

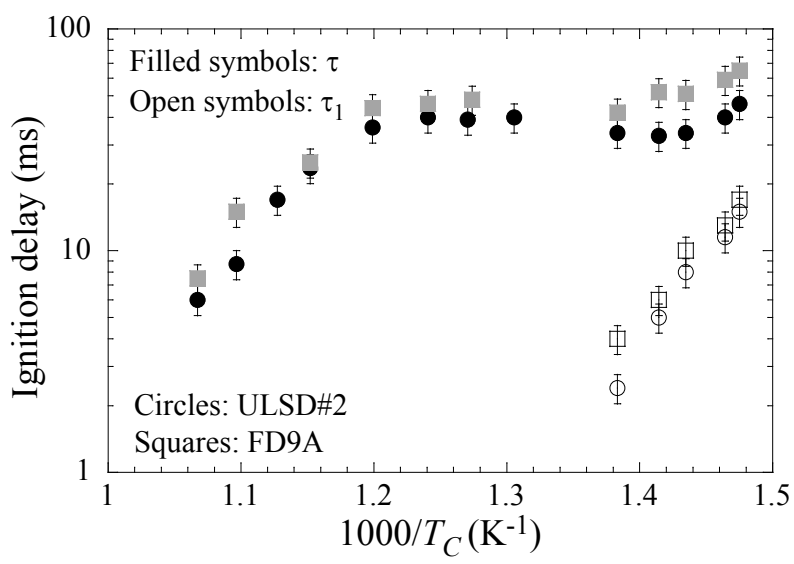

(c) $\phi=1.02, P_{C}=15$ bar

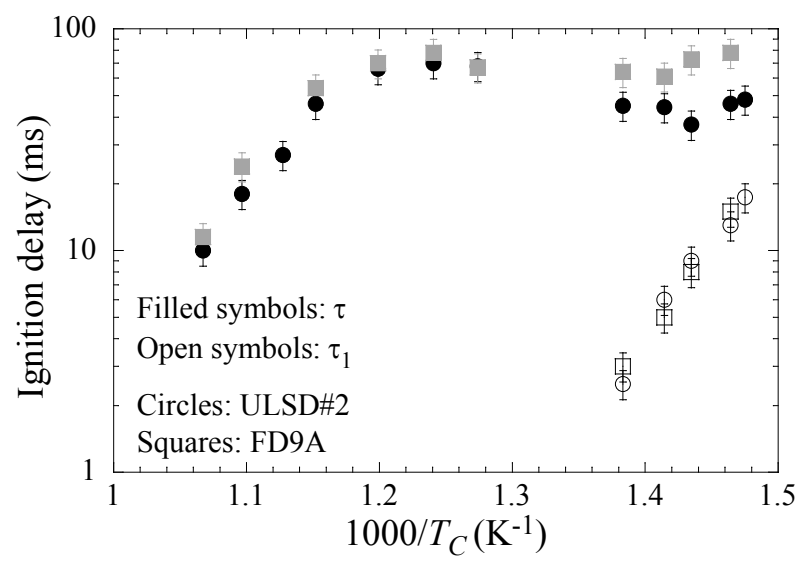

(e) $\phi=0.69, P_{C}=10$ bar

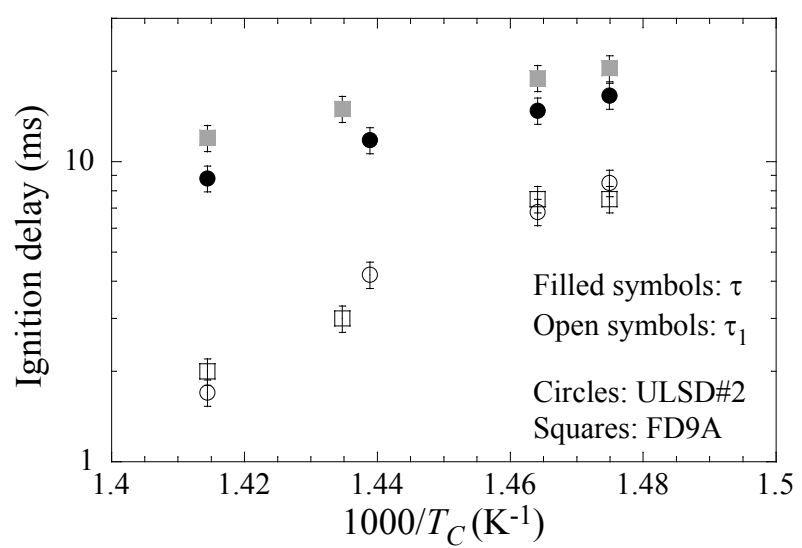

(b) $\phi=0.5, P_{C}=20$ bar

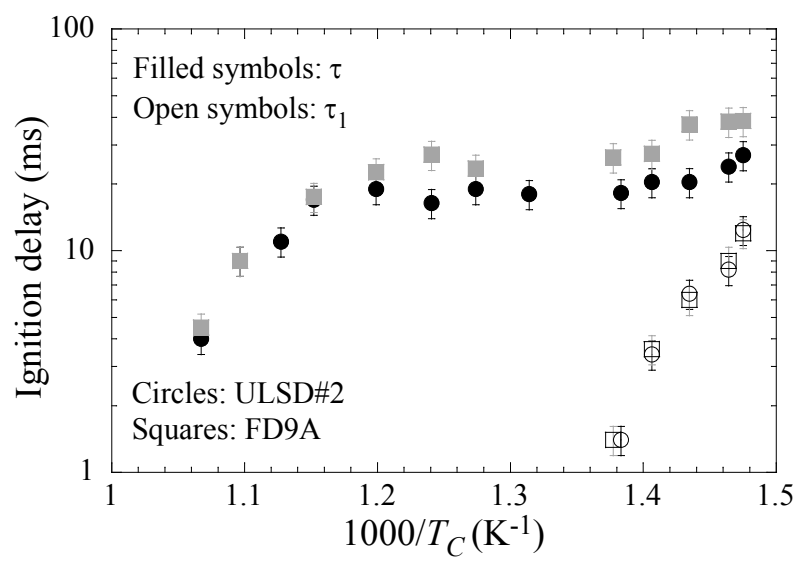

(d) $\phi=0.69, P_{C}=15 \mathrm{bar}$

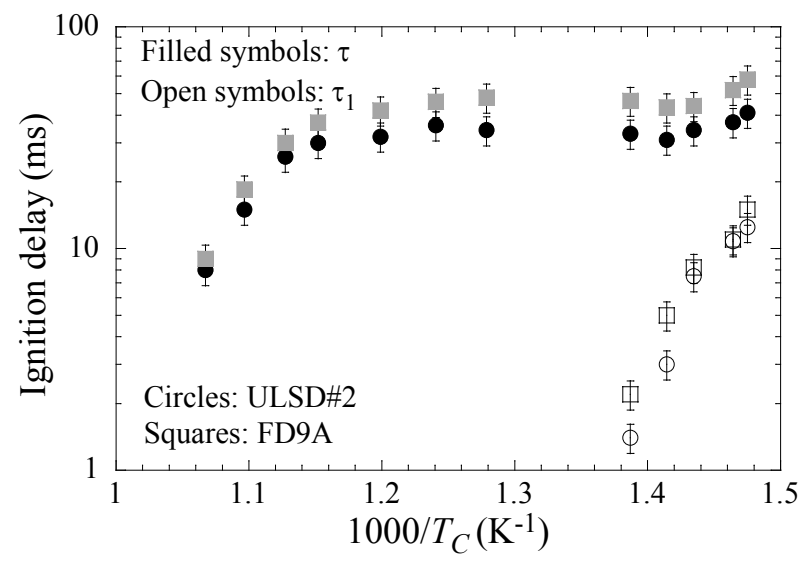

(f) $\phi=0.5, P_{C}=10 \mathrm{bar}$

Figure 9 


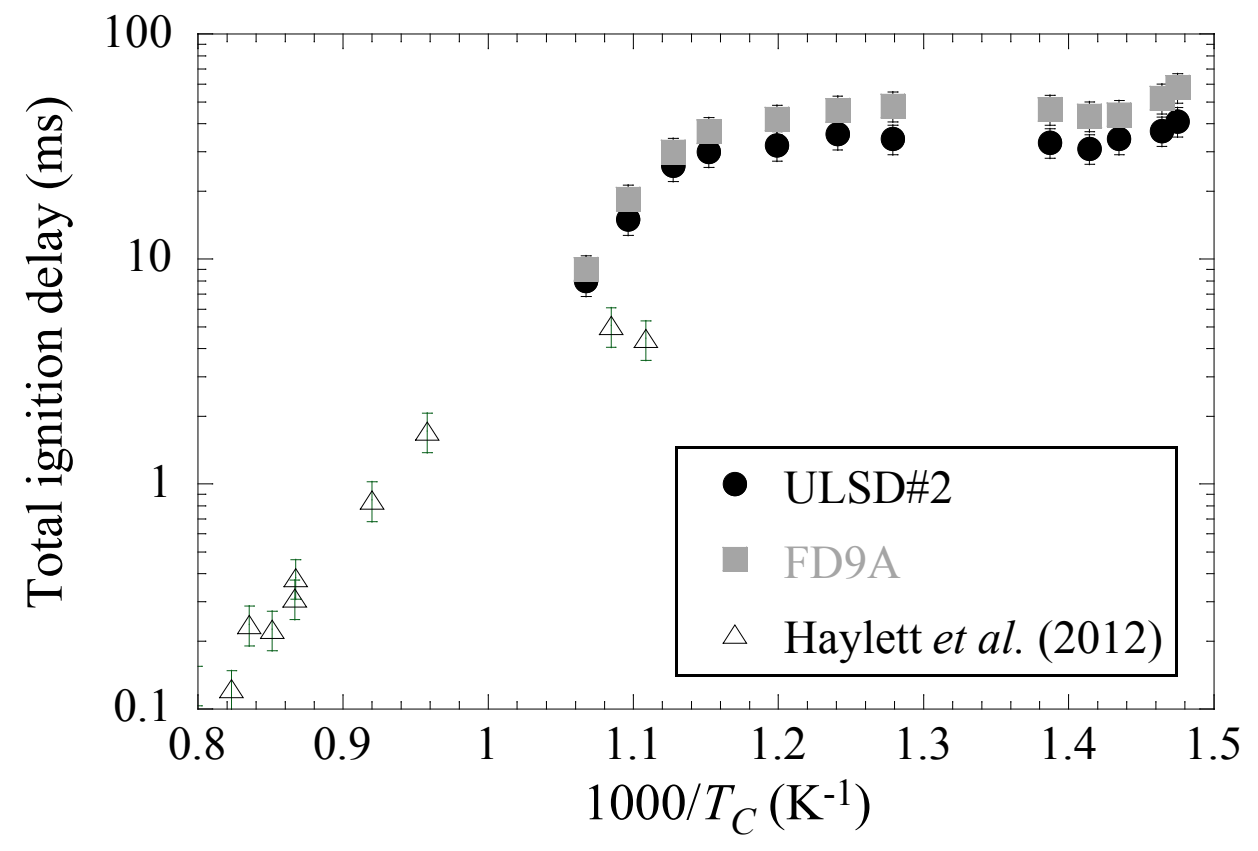

(a) $P_{C}=10$ bar, $\phi=0.5$

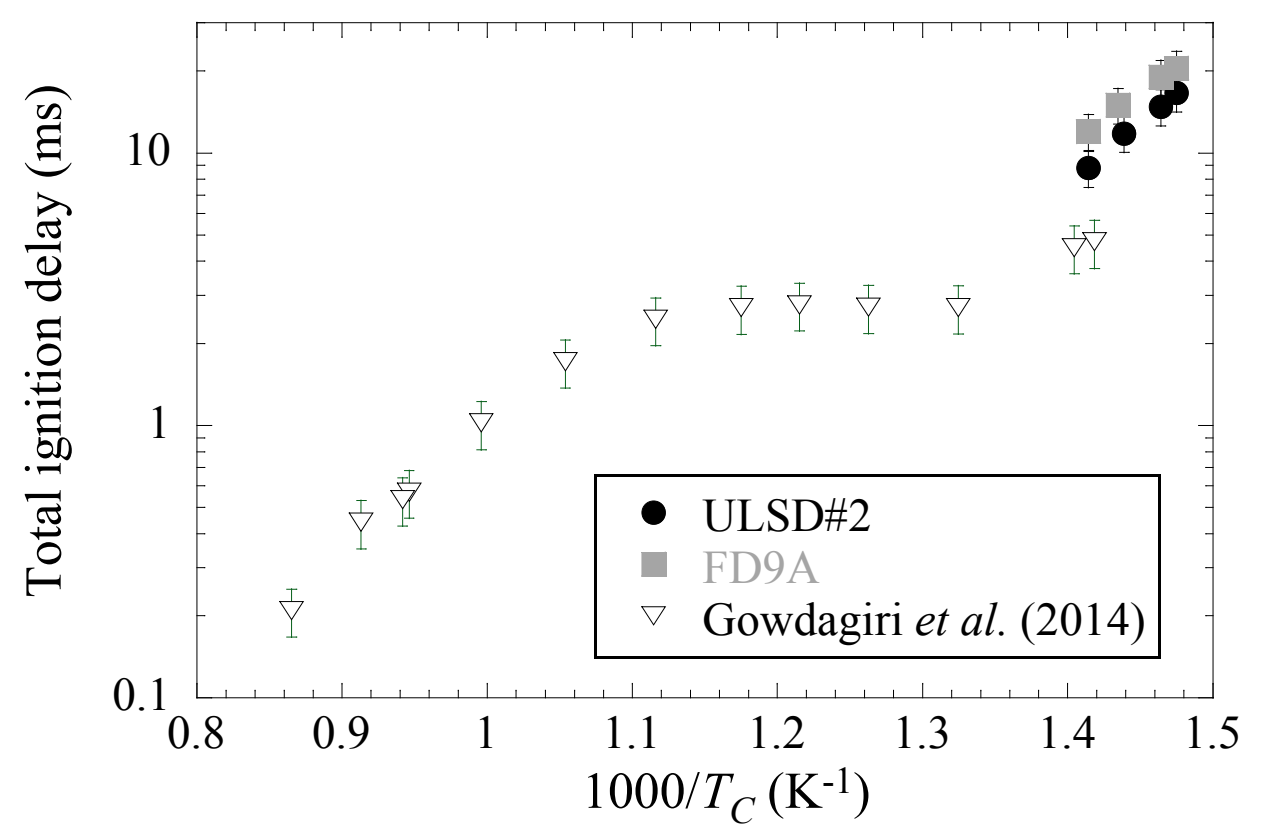

(b) $P_{C}=20$ bar, $\phi=0.5$

Figure 10 
Table 1

\begin{tabular}{|l|c|c|c|c|c|}
\hline \multicolumn{1}{|c|}{ Study } & Facility & Pressure $(\mathrm{atm})$ & Temperature (K) & $\phi$ & Oxidizer \\
\hline Spadaccini and Tevelde [5] & Flow Reactor & $10-30$ & $625-1000$ & $0.3-1$ & Air \\
\hline Penyazkov et al. $[6]$ & Shock Tube & $4.7-10.4$ & $1065-1838$ & $0.5-2$ & Air \\
\hline Haylett et al. $[8]$ & Shock Tube & $1.7-8.6$ & $947-1261$ & $0.2-1$ & varying $\mathrm{O}_{2} /$ Ar ratios \\
\hline Gowdagiri et al. $[9]$ & Shock Tube & 10,20 & $671-1266$ & $0.5,1$ & Air \\
\hline
\end{tabular}

Table 2

\begin{tabular}{|c|c|c|c|}
\hline Property/Composition & ULSD\#2 & FD9A & F-76 \\
\hline $\mathrm{H} / \mathrm{C}$ ratio $^{[9,12]}$ & 1.80 & 1.80 & 1.80 \\
\hline $\mathrm{DCN}^{[9,12]}$ & 43.7 & 44.2 & 48.8 \\
\hline $\mathrm{CN}^{[12]}$ & 43.3 & 43.9 & - \\
\hline Density $\left(\mathrm{kg} / \mathrm{m}^{3}\right)^{[12]}$ & 848 & 846.2 & - \\
\hline Heat of combustion $(\mathrm{MJ} / \mathrm{kg})^{[12]}$ & 42.90 & 42.86 & - \\
\hline Saturates (\% weight) ${ }^{[9,13]}$ & 69.85 & 65.20 & 82 \\
\hline iso-Alkanes & 18.44 & 22.37 & 20 \\
\hline n-Alkanes & 16.38 & 11.13 & 56 \\
\hline Cycloalkanes & 35.03 & 29.05 & 6 \\
\hline Aromatics (\% weight) ${ }^{[9,13]}$ & 30.05 & 34.67 & 16 \\
\hline Alkylbenzenes & 9.83 & 21.55 & - \\
\hline Indanes/Tetralins & 8.13 & 10.77 & - \\
\hline$>2$ aromatic rings & 12.09 & 5.04 & 2 \\
\hline Others $^{[9,13]}$ & 0.10 & 0.13 & 2 \\
\hline
\end{tabular}

Table 3

\begin{tabular}{|c|c|c|c|c|}
\hline$\phi$ & $\mathrm{X}_{\text {diesel }}$ & $\mathrm{X}_{\mathrm{O} 2}$ & $P_{C}($ bar $)$ & $T_{C}(\mathrm{~K})$ \\
\hline 0.5 & $0.514 \%$ & $20.9 \%$ & 10,20 & $678-938$ \\
\hline 0.69 & $0.514 \%$ & $15.12 \%$ & 10,15 & $678-938$ \\
\hline 1.02 & $0.514 \%$ & $10.24 \%$ & 15,20 & $678-938$ \\
\hline
\end{tabular}

